\title{
Substandard derivations as objects of system analysis: derivational homonyms
}

\section{[Субстандартное словообразование как объект системного анализа: словообразовательная омонимия]}

\author{
Elena V. Habibulina
}

\section{DOI: $10.18355 / X L .2015 .08 .01 .50-56$}

\begin{abstract}
Аннотация предметными значениями.

Ключевые слова

Субстандартное словообразование, аффикс, омонимия
\end{abstract}

В данной работе предметом исследования явление словообразовательной омонимии в системе субстандартной деривации. Рассматриваются случаи аффиксальной омонимии, выявленные на материале жаргонных лексем, а также возможности и механизмы возникновения омонимии при заимствовании субстандартом морфемы, закрепленной в словообразовательной системе книжных стилей языка. Доказывается справедливость точки зрения ученых Казанской лингвистической школы на существование в русском языке омонимии суффиксов имен со значениями отвлеченного действия и имен с

Словообразование представляет динамический аспект языка и является одной из составляющих его развития, в связи с этим изучение деривационных процессов не может не быть актуальным и вопросы исторического и современного словообразования постоянно привлекают внимание лингвистов. Объектом их исследования часто становились словообразовательные явления русского языка в разные периоды его развития (В.В. Виноградов, Э.А. Балалыкина, А.А. Дементьев, Е.А. Земская, Г.С. Зенков, Г.А. Николаев, Т.М. Николаева, Н.М. Шанский и др.). Процесс осмысления словообразовательных категорий будет продолжаться и впредь, так как, с одной стороны, словообразовательные процессы продолжают функционировать в системе языка, a c другой - развивается наука о словообразовании, и многие словообразовательные явления могут быть рассмотрены с новых позиций. С совершенствованием теоретической базы естественно должны изменяться подходы к рассмотрению фактического материала. Впрочем, и фактический материал, вовлекаемый в деривационные исследования, - явление не статичное. Так, в последние 25 лет можно констатировать неослабевающий интерес лингвистов к изучению субстандартной лексики, в том числе в деривационном аспекте (М.А. Грачёв, В.С. Елистратов, Л.П.Крысин, А.Т. Липатов, В.В. Химик и др.), достаточно активно разрабатывается данная тема в диссертациях, посвященных молодежному жаргону (М.В. Барт, О.Н. Федянина, В.Н. Андреев, Т.В. Зайковская, Н.А. Джеус, Е.Н. Казачкова, Чжао Сяохэн, Е.А. Рубцова и др.). Цель настоящей работы - обратить внимание на некоторые проблемы, рассмотрение которых остается на периферии внимания исследователейдериватологов, работающих с субстандартом.

\section{Методы}

Методы, использованные при подготовке данного материала, описательный, сопоставительный, метод структурного и мотивационного словообразовательного анализа, метод компонентного анализа. 
На данный момент лингвистами, работающими в данной области, подробно проанализированы способы деривации, определен круг наиболее частотных морфем в субстандартных лексемах, описаны аффиксы, специфические для субстандарта. Однако некоторые моменты, например, вопрос о системных отношениях в субстандартной деривации, остаются недостаточно исследованными. К числу таковых относится и явление словообразовательной омонимии.

Говоря о словообразовательных омонимах, виднейший представитель Казанской лингвистической школы профессор В.М. Марков писал о формировании омонимии словообразовательных морфем так: «В результате всё более последовательного осуществления семантического словообразования по аналогии в сфере морфемных образований последние могут усваивать новое типовое значение, что приводит к возникновению новых словообразовательных морфем в силу закрепления новых ассоциаций между значением и формой» (Markov, 1981: 22). Этой же точки зрения придерживается его ученик и последователь - профессор Г.А. Николаев, указывая на то, что возникшая омонимия морфем приводит к распаду словообразовательных типов на омонимичные типы (Nikolaev, 1985: 80).

\section{Результаты}

Ученые, развивающие взгляды Казанской лингвистической школы, считают, что в русском языке существует омонимия суффиксов имен со значениями отвлеченного действия и имен с предметными значениями (посадка - процесс, а также место действия и результат действия). Не все исследователи склонны, однако, видеть в подобных случаях именно омонимию, например, Д. Осильбекова говорит о том, что здесь имеет место полисемия: «Специфика полисемии суффиксов имён действия заключается в том, что ее формируют два типа семантических отношений. К первому типу относится связь абстрактного значения действия и конкретного значения 'предмет, характеризующийся действием’. Значение действия является общим семантическим компонентом двух значений - транспозиционного и мутационного: 'действие как процесс' и ‘предмет, характеризующийся действием'. Второй тип отношений связывает предметные значения» (Osil'bekova, 2009:301). Наличие в семантике производного слова общего элемента «действие» является, по мнению Д.Осильбековой, решающим фактором для того, чтобы определить ситуацию как полисемию суффикса. Но тогда в словах типа веялка и караулка суффикс лк- также представляет собой полисемичную морфему, так как в обоих случаях в семантике элемент «действие» также присутствует («предмет, предназначенный для выполнения действия» и «место, предназначенное для осуществления действия»). Однако ни в первом, ни во втором случае абстрактного значения не существовало, единственным словообразовательным значением является предметное.

На наш взгляд, доказательство того, что в случае с оформлением одним суффиксом предметного и отвлеченного значений имеет место именно омонимия, можно обнаружить в материале жаргонного словообразования, так как аффиксальная омонимия существует не только в русском литературном языке, но и в субстандарте. Так, в субстандартной деривации имеется достаточно продуктивный, как отмечают многие исследователи, суффикс -он. Говоря об этимологии этого аффикса, А. Зализняк указывает, что он появился из квазиморфемы -онт, использовавшейся в бурсацкой среде как подражание греческому - изначально появляется опрокидонт, упрощающееся затем до 
опрокидон, хронологически вслед за ним идут выпивон и закусон (закуска) (Zaliznjak, 2012: 664).

С точки зрения синхронии с помощью данного аффикса в современном жаргоне от глаголов образуются слова со значением отвлеченного действия: расслабиться - расслабон, задвигать - задвигон и т.д. Наряду с процессуальными значениями, отглагольные дериваты на -он приобретают результативное или предметное значение, например, лексема выпивон обозначает как процесс распития спиртных напитков, так и сами спиртные напитки, залепон (от залепить) - результат действия (промах, глупость). И, наконец, есть отглагольные дериваты с элементом -он, имеющие только предметное значение: обстригон (прическа), вышибон (последний танец перед закрытием ресторана). Таким образом, здесь, действительно, налицо омонимия словообразовательных морфем, представленная в развитии: как и в литературном языке, дериват с абстрактным значением сначала приобретает в результате семантического словообразования конкретное значение, а затем устанавливает соотнесенность непосредственно с глаголом, «на базе которого возникло его производящее» (Nikolaev, 1985: 61).

Отметим, что аффикс -он продуктивен и как морфема, участвующая в производстве дериватов с модификационными значениями. Производящей основой для имен на -он являются существительные: репетиция - pепетон, тусовка - тусон, отрыгон (от отрыжка - «что-л.неприятное»), вьетнамон (вьетнамеи), музон (от музыка), прикидон (от прикид - «одежда»), преподон (от препод - «преподаватель»), стипон (от стипендия), лифон (от лифчик), тубзон (от тубзик - «туалет»). Его продуктивность в жаргонной речи, безусловно, обусловлена высокой степенью экспрессии.

Не менее выразительны и рассмотренные нами отглагольные дериваты, об этом свидетельствует наличие синонимических рядов типа задвиг - задвигон, завис - зависон, где синонимом к деривату на -он выступает лексема, образованная путем нулевой суффиксации. Считается, что продуктивность слов с нулевыми суффиксами в жаргонной речи обусловлена именно их экспрессивностью но, очевидно, уровень экспрессии элемента -он в сознании носителей жаргонной речи воспринимается как еще более высокий.

Итак, в современном жаргоне элемент -он может представлять собой три омонимичных аффикса, которые участвуют в производстве слов с отвлеченным и предметным значением, общим для дериватов всех трех типов является наличие яркой стилистической окраски.

Рассмотрим еще два примера жаргонизмов, демонстрирующих механизм развития омонимии в языке. Интересный случай словообразовательной омонимии мы наблюдаем у дериватов, имеющих в своем составе элемент -оз-. Здесь причиной совпадения являются уже не семантические преобразования, произошедшие с морфемой в процессе ее существования в языке, но случайное совпадение. Рассматриваемый элемент мы находим в словах химоза, нервоза, китаёз(а), рогаликоз, актоз, опупеоз. В этом ряду нет примеров, которые относились бы к одному словообразовательному типу. Так, лексема актоз - «актовый зал», вероятнее всего, представляет собой аббревиатуру, здесь, в отличие от других примеров, -оз- суффиксальной морфемой не является.

Слова химоза и нервоза, используемые в школьном жаргоне, обозначают лицо женского пола (первое - «учительница химии», второе «раздражительная учительница»). Словообразовательная модель в первом случае имеет следующий вид: химия + -оз(а), лексема образована по аналогии с наименованиями химических веществ (сахароза, фруктоза, рибоза). При этом 
суффикс -оз-, являющийся специфической морфемой для обозначения веществмоносахаридов, выступает для производства наименования лица. В слове нервоза модель иная, так как -оз- здесь не является словообразующей морфемой, а входит в состав производящей основы, подвергающейся усечению: нервозн(ый), по этой же модели образовано слово стервоза.

Существительное мужского рода китаёз (употребителен также вариант общего рода китаёза) имеет значения «китаец», «азиат». Современный носитель языка выделяет в нем производящую основу Китай и словообразующий элемент -о3-, однако в русском языке среди суффиксов, использующихся для деривации наименований лица по отношению к местности, стране или населенному пункту, морфемы -оз- нет. Составители словарей субстандартной лексики не объясняют происхождение лексемы китаёза, есть предположения о заимствованном характере аффиксальной морфемы: французское -euse или английское -ese. Данная версия имеет право на существование, как, впрочем, и предположение, что здесь мы имеем дело с шутливым искажением русского слова «китаец» - пародией на «китайский» акцент. Подчеркнем еще раз, что сейчас слово китаёз является для носителей языка мотивированным словом Китай, таким образом, элемент -оз- приобретает статус словообразующего суффикса, использующегося для наименования лица по национальности.

Слово рогаликоз («благоприятная ситуация, удачное стечение обстоятельств») дается в Толковом словаре русского сленга как образованное по той же модели, как лексема невроз. В русском литературном языке суффикс -озявляется заимствованным и знаком носителям языка преимущественно по медицинской терминологии в словах со значением «заболевание чего-либо», «патологическое состояние». Сленговая лексема рогаликоз имеет шутливую окраску и обозначает состояние, характеризующееся положительно, т.е. можно констатировать тот факт, что в семантике суффикса -оз- произошли изменения, поскольку стирается та негативная коннотация, которая сопровождает слова со значением болезни или патологического состояния, образованные с помощью данной морфемы в литературном языке. Но обычно книжные и нейтральные морфемы, имеющие отрицательную коннотацию и используемые как средства деривации в сленге и арго, подобных семантических изменений не претерпевают. Можно выдвинуть предположение, что элемент -оз- в рассматриваемой лексеме появился под влиянием грецизма апофеоз, тем более что в сленге достаточно давно существует дериват опупеоз, со значением «пик, максимум чего-либо», «что-либо, вызывающее сильные эмоции», представляющее собой результат контаминации слов опуnеть и апофеоз. Элемент -оз- выступает в нашем случае как суффиксальная морфема, с помощью которой от субстантивной основы рогалик образуется слово со значением состояния - рогаликоз. Подытоживая вышесказанное, мы видим, что элемент -оз- в субстандартной лексике, выступая в качестве аффикса, может представлять собой омонимичные морфемы, с помощью которых образуются: 1) наименование лица женского пола по отношению к тому, что указано в производящей основе, 2) наименование лица по национальности, 3) наименование состояния. Изначально звуковое совпадение здесь является абсолютно случайным.

Следует отметить и те случаи омонимии словообразовательных единиц, которые возникают при освоении субстандартом морфемы из литературного языка. Так, аффиксальный элемент -оид в литературном русском языке морфема, имеющая книжную стилистическую окраску, употребляющаяся, прежде всего, в составе научных терминов. В словаре Т.Ф. Ефремовой ее 
значение определяется следующим образом: «Словообразовательная единица, образующая имена существительные мужского рода со значением лица, которое подобно тому, что названо мотивирующим именем существительным негроид (и т.п.)» (Efremova, 2000). В жаргонном словообразовании данная морфема приобретает иную эмоционально-экспрессивную окраску, чаще всего выражая негативное, ироническое или пренебрежительное отношение говорящего к называемому объекту. В словарях зафиксированы дериваты алгеброид (учитель алгебры), чеченоид (чеченец, кавказец), терапоид (терапевт), сникерсующий соплоид (подросток, жующий сникерс, о любом молодом человеке, увлекающемся рекламируемыми товарами), ельцииноид, андропоиды (кремлевские руководители). Словообразовательный потенциал данной морфемы достаточно высок, производные с элементом -оид, не зафиксированные составителями словарей, обнаруживаются в речи участников интернет-форумов: линуксоид, кубаноид, дубиноид (полуторный мессердубиноид хорош как серъёзное оружие против групповой опасности когда дробить и разбивать надо), балдоид, гнилоид, ужасоид, смехоид, кочмароид, приколоид, дружбаноид, физикоид.

Значение аффикса -оид в жаргонной речи претерпевает изменения. Дериваты на -оид не только указывают на подобие именуемого тому, что названо мотивирующим именем (дубиноид, козлоид, ужасоид, гнилоид, водилоид), но, как свидетельствуют данные интернет-форумов, могут называть лицо по его увлечению чем-либо, интересу к чему-либо например, линуксоид активный пользователь Linux:

ИМХО надо просто написать коллективный портрет

$>$ линуксоида. линуксофила.

$>$ Кстати, англицкое синоним рускому линуксоиду linuхапt

( http ://asplinux.net/node/7049)

Из приведенного фрагмента видно, что аффикс -оид рассматривается пишущим как синонимичный элементу -фил. Появление данного значения у суффикса -оид, на наш взгляд, можно проследить на примере лексемы ельциноид, зафиксированной в словарях субстандарной лексики. Называя сторонников политики Б.Н. Ельцина, данный дериват указывает на то, что эти люди подобны Ельцину (по политическим взглядам), т.е. являются сторонниками его взглядов (*ельцинофилами): налицо определенный синкретизм. Но в деривате линуксоид изначально значение подобия чему-, комулибо заложено не было. Таким образом, мы наблюдаем здесь случай, когда морфема с книжной стилистической окраской, попадая в арсенал словообразовательных средств жаргонной речи, приобретает новый оттенок значения, что в итоге приводит к развитию словообразовательной омонимии.

Как и аффикс -он, аффикс -оид может выступать в качестве средства производства дериватов с модификационными значениями - это становится возможным в силу интенсивности его эмоционально-экспрессивной окраски; в результате появляются дериваты типа дружбаноид («друг» - от дружбан), приколоид (прикол), в которых мы можем наблюдать нанизывание аффиксов, характерное для жаргонной речи.

Интересна рефлексия лингвистов в связи с уточнением значения данного словообразовательного элемента. Приведем высказывание, найденное нами на одном из интернет-сайтов:

Я нашла несколько обсуждений на форумах в Интернете по поводу значений этого слова. Ясно, что сформировавшегося значения слово кубаноид не имеет: один носитель языка употребил его в положительном значении, другой - в отрицательном. Какие-то употребления вообще не содержат оценки, они 
нейтральны. Вот примеры вкладываемых в слово кубаноид смыслов: "коренной житель Кубани", "мигрант, переехавший на Кубань из более северных регионов России", "житель сельской местности Кубани", "житель Краснодара со столичным снобизмом", "отдыхающий из станицы", "обслуживающчий персонал на курортах Краснодарского края", "недалекий, ограниченный, малограмотный", "хитрый, расчетливый, умный", "прижсимистый, жадный, завистливый, взяточник", "человек, в чьей речи узнается кубанский говор", "человек, который любит поесть". И это только часть возможных значений (фрагмент интервью с доцентом кафедры русского языка Ивановского государственного университета Э. Кромер, включенного в книгу журналиста Анны Червяковой «К.Рай» взят с портала Южного региона http://people.yuga.ru/articles/teplo-i-lyudi/18.html). На примере этих рассуждений мы отчетливо видим, что суффикс -оид, использующийся в литературном языке, и суффикс -оид, являющийся средством жаргонной деривации, семантически настолько различны, что мы можем вести речь именно об омонимии рассматриваемых единиц.

\section{Заключение}

Итак, мы рассмотрели лишь один вопрос, связанный с необходимостью исследования субстандартного словообразования уже не в описательном аспекте, а как системного явления, нуждающегося в синхроннодиахронном изучении. При этом должна учитываться как специфика деривационных особенностей в субстандарте, например, в жаргонах и арго, так и те процессы и явления, которые являются общими для разных языковых пластов. Результаты исследований в этой области, несомненно, позволят не только сделать лексикографические описания в словарях субстандарта более точными, но могут быть полезными для освещения процессов и явлений, характерных для словообразования русского литературного языка.

\section{References}

ANISHHENKO, O. 2010. Genezis i funkcionirovanie molodezhnogo sociolekta v russkom jazyke nacional'nogo perioda: monografija. Moskva: Flinta: Nauka. ISBN: 978-5-9765-0915-3, 978-5-02-037236-8

BALALYKINA, JE. - NIKOLAEV, G. 1985. Russkoe slovoobrazovanie: Ucheb. posobie. Kazan': Izd-vo Kazan. un-ta.

BELOUSOV V.N. i dr., 1989. Kratkaja russkaja grammatika. Moskva: Russkij jazyk. ISBN 5-200-00726-7.

CYBULEVSKAJA, A. 2005. Jemotivnyj argoticheskij leksikon: dis... kand. filolog, nauk: 10.02.19 / Cybulevskaja Anna Vasil'evna. Stavropol'. 176 s.

EFREMOVA, T. 2000. Novyj slovar' russkogo jazyka. Tolkovo-slovoobrazovatel'nyj. M.: Rus. jaz. ISBN 5-200-02800-0

ELISTRATOV, V. 2005. Tolkovyj slovar' russkogo slenga: svyshe 12000 slov i vyrazhenij, argo, kinemalogos, zhargony». M.: «AST-Press kniga». ISBN 5-46200441-9, ISBN 978-5-462-00441-4

GRACHJOV, M. 1997. Russkoe argo: monografija. N. Novgorod. ISBN 5-85839042-0

GRACHJOV, M. 2007. Slovar' sovremennogo molodezhnogo zhargona: bolee 6000 zhargonizmov. M.: Eksmo. ISBN 5-699-14614-8

GRACHJOV, M. - MOKIENKO, V., 2008. Russkij zhargon: ist.-jetimol. slov. M.: AST-Press, 2008. ISBN 978-5-462-00794-1

HIMIK, V. 2004. Bol'shoj slovar' russkoj razgovornoj jekspressivnoj rechi. S-Pb: «Norint». ISBN 5-771-10202-4, ISBN 978-5-771-10202-3 
JANKO-TRINICKAJA, N. 2001. Slovoobrazovanie v sovremennom russkom jazyke. M.: Izd-vo «Indrik». ISBN: 5-85759-169-4

KRYSIN, L. 2007. Ob internacionalizacii fonda slovoobrazovatel'nyh morfem. V: Sovremennoe russkoe jazykoznanie i lingvodidaktika. Vyp. 2. M.: MGU. ISBN 9785-7017-1133-2

LIPATOV, A. 2010. Sleng kak problema sociolektiki. Moskva: Jelpis.. ISBN: 978-5902872-31-3

MARKOV, V. 1981. O semanticheskom sposobe slovoobrazovanija v russkom jazyke. Izhevsk: UdGU.

MARKOV V. 2001. Izbrannye raboty po russkomu jazyku. Kazan': DAS, 2001. ISBN 5-8185-0036-5

MOKIENKO, V. - NIKITINA, T., 2000. Bol'shoj slovar' russkogo zhargona: 25000 slov, 7000 ustojchivyh sochetanij». S-Pb: Sankt-Peterburgskij gosudarstvennyj universitet. ISBN 5-771-10091-9, ISBN 978-5-771-10091-3

NIKOLAEV, G.- BALALYKINA, E. 1985. Russkoe slovoobrazovanie. Uchebnoye. posobie. Kazan': Kazan.un-t.

NIKOLAEV, G. 2010. Russkoe istoricheskoe slovoobrazovanie: Teoreticheskie problemy. Izd.2, dop. M: URSS. ISBN 978-5-397-01265-2

NIKOLAEV, G. 2011. Teoreticheskie problemy russkogo slovoobrazovanija. Kazanskaja lingvisticheskaja shkola. V: Russkoe i slavjanskoe slovoobrazovanie: Opera selecta. Kazan': Kazan.un-t. - S. 4 - 19. ISBN: 978-5-98180-881-4.

NIKOLAEV, G. 2011. Vzaimodejstvie morfologicheskogo i semanticheskogo slovoobrazovanija v slavjanskih jazykah. V: Russkoe i slavjanskoe slovoobrazovanie: Opera selecta. Kazan': Kazan.un-t. - S. 32 - 36. ISBN: 978-5-98180-881-4

OSIL'BEKOVA, D. 2009. Kriterii omonimii slovoobrazovatel'nyh affiksov. V: Vestnik TGU. Serija Gumanitarnye nauki. Filologija. № 1. S.29-34. ISSN 1810-0201

RACIBURSKAJA, L. 1998. Unikal'nye morfemy v sovremennom russkom jazyke. M.: Prometej. ISBN 5-7042-0896-7

RACIBURSKAJA, L. 2009. Slovar' unikal'nyh morfem sovremennogo russkogo jazyka. M.: Flinta: Nauka. ISBN 978-5-89349-868-4 (Flinta), ISBN 978-5-020333377-6 (Nauka)

ULUHANOV I.S. 2012. Slovoobrazovanie. Morfonologija. Leksikologija. - M.: Izdatel'stvo "Logos". ISBN 978-5-8163-0092-6

ULUHANOV I.S. 2008. Edinicy slovoobrazovatel'noj sistemy russkogo jazyka i ih leksicheskaja realizacija. Moskva: URSS. ISBN 978-5-382-00814-1

ZALIZNJAK, A. 2012. Mehanizmy jekspressivnosti v jazyke. V: Smysly, teksty i drugie zahvatyvajushhie sjuzhety. Sbornik statej v chest' 80-letija I. A. Mel'chuka. M.: «Jazyki slavjanskoj kul'tury». S.650 - 664. ISBN 978-5-9551-0593-2

ZEMSKAJA, E. 2005. Sovremennyj russkij jazyk. Slovoobrazovanie: Ucheb. posobie. M.: Flinta: Nauka. ISBN 5-89349-634-5 (Flinta), ISBN 5-02-033011-6 (Nauka)

Words: 2627

Characters: 21761 (12,09 standard pages)

Assoc. Prof. Elena Viktorovna Habibulina, PhD (Philology)

Department of Russian as a Foreign Language

Institute of Philology and Intercultural Communication

Kazan (Volga) federal university

Kremlovskaya 18

420008 Kazan

Russia

elvikh@mail.ru 